\title{
Steel Fibre Reinforced Concrete Meso-Scale Numerical Analysis
}

\author{
Zhengwei Li $\mathbb{D}$, ${ }^{1}$ Meizhong Wu $\mathbb{D},^{2}$ Jiawei Wu $\mathbb{D},{ }^{2}$ Yujun Cui $\mathbb{D},{ }^{2}$ and Xingwei Xue $\mathbb{D}^{2}$ \\ ${ }^{1}$ Guangzhou Communications Investment Group Co.,Ltd, Guangzhou, Guangdong 510000, China \\ ${ }^{2}$ School of Traffic Engineering, Shenyang Jianzhu University, Shenyang, Liaoning 110168, China \\ Correspondence should be addressed to Xingwei Xue; gdansys@163.com
}

Received 25 January 2020; Revised 30 October 2020; Accepted 27 November 2020; Published 24 December 2020

Academic Editor: Timo Saksala

Copyright $\odot 2020$ Zhengwei Li et al. This is an open access article distributed under the Creative Commons Attribution License, which permits unrestricted use, distribution, and reproduction in any medium, provided the original work is properly cited.

Concrete is a heterogeneous composite consisting of aggregate, cement paste, and void. Steel fibre reinforced concrete (SFRC) has been widely studied experimentally and numerically in recent decades. The fibre geometry model program generated by a secondary development ANSYS program was exported to midas FEA for analysis. The constitutive concrete model adopts the total strain crack model of concrete. A steel fibre bond slip is considered in an equivalent manner using the von Mises model. The results of the three-dimensional meso-scale numerical analysis method agree well with the experimental values of steel fibre concrete beams.

\section{Introduction}

Concrete is a typical heterogeneous composite consisting of aggregate, cement paste, and void. This heterogeneity can be amplified by the addition of fibres. When added to concrete, steel fibres not only significantly improve its postcracking tensile resistance and toughness, but its impact resistance, fatigue resistance, and durability are also greatly improved [1-6]. In addition to testing, meso-scale modelling provides a way to choose materials and fibres. Meso-scale concrete simulation is utilised for evaluation of chloride penetration [7-9], carbonation [10-12], corrosion [13-15], elevated temperature [16], and aggregate shapes [17, 18]. More importantly, the mechanical analysis of concrete can be performed through meso-scale simulation. To explore the mechanical properties of steel fibre reinforced concrete (SFRC), numerous experimental and numerical studies have been performed in this area.

For the SFRC force analysis, scholars mainly research and summarise the static $[19,20]$ and dynamic loads [21-23]. Yasmin et al. [19, 20] analysed postcracking material behaviour by static load testing and simulation. This study investigated the applicability of a recently proposed multiscale model with discrete and explicit representation of steel fibres to obtain the SFRC postcracking parameters.
Under the action of a dynamic load, Xu Z. et al. [21] presented a numerical simulation of dynamic impact tests on SFRC specimens to study the dynamic material properties of SFRC using LS-DYNA and investigated the dynamic failure behaviour of SFRC material under impact loading at different strain rates. A 3D numerical model has been proposed by Fang and Zhang [22] to investigate the mechanical properties of SFRC material under intense dynamic loading. Numerical analysis showed that steel fibres in concrete could improve the elastic modulus and the peak strain of SFRC material at a high strain rate. Hao et al. [23] investigated the influence of the shape of aggregates on numerical prediction in meso-scale modelling of SFRC materials with spiral fibres under dynamic splitting tension.

Many studies [24-27] have compared the experimental results with the results of finite element analysis (FEA) and found that the simulated results strongly agree with the experiment. Reliability analyses of SFRC corbels based on stochastic finite elements were performed for the first time by Gulsan [24]. Research on SFRC mechanical properties involved experiments by Sun et al. (2017) [25], where ANSYS finite element software of two SFRC T-beams and one concrete T-beam was used. Vítor [26] simulated the behaviour of SFRC. Jingu [27] established a finite element model distributed-force approach that simulated the transfer 
of crack bridging forces over the fibre embedment lengths and their associated effects on cracking behaviour. The experimental and numerical results prove that numerical analysis is an important tool for SFRC research.

The use of finite element software can make it easier to study the SFRC interface [28-30] and derive an SFRC numerical constitutive model [31-33], secondary development, and application [34]. In 2010, Radtke [28] proposed to build a model using the concept of discrete fibre. The SFRCs are modelled by applying discrete forces to a background mesh to analyse the behaviour of the fibre-matrix interface. Pros et al. [29] applied the numerical immersed boundary approach and a phenomenological meso-model for concretefibre interaction. Liang and $\mathrm{Wu}$ [30] modelled fibre and concrete separately and linked them with slide line contact to truly reflect the interfacial behaviour of fibre and mortar. Guillermo [31] (2012) used the discrete crack formula to simulate the constitutive, mesoscopic, and macroscopic observations of the SFRC fracture behaviour. Qi et al. [32] proposed a constitutive model, including a bilinear model for compression and a drop-down model for tension. The finite element model established by Luís [33] applied a constitutive damage model.

For the concrete mechanical analysis of meso-scale simulation, this study focuses on (1) the establishment of random fibres and (2) the relationship between fibres and the matrix. This study used ANSYS to generate a three-dimensional geometric program of randomly distributed fibres; then, the geometric model was imported into midas FEA for nonlinear analysis and compared with the existing flexural test and direct tensile test. The von Mises model is adopted to represent the equivalent of bond slippage of steel fibre.

\section{Generation of Geometric Model of Randomly Distributed Fibres}

The SFR in the SFRC three-dimensional meso-scale numerical model should be uniformly and randomly distributed in the concrete matrix. This study uses ANSYS parametric design language (APDL) to conduct secondary development of ANSYS and write a fibre parameterisation program that generates linear fibres in specified cubes, which can quickly and effectively generate geometric models of randomly distributed fibres in a specified cube. The fibre geometry model is then imported into a professional finite element software for analysis. The basic modelling scheme of the fibre geometry model program is as follows.

\section{Step 1. Generation of fibre origin point $K_{\mathrm{i}}$}

In the global coordinate system, within the specified cube space $\left\{0, X_{0} ; 0, Y_{0} ; 0, Z_{0}\right\}$, the starting point $K_{\mathrm{i}}$ of the fibre is generated. Use a random function to generate the $X$ coordinate $X_{\mathrm{i}}, Y$ coordinate $Y_{\mathrm{i}}$, and $Z$ coordinate $Z_{\mathrm{i}}$ of the starting point $K_{\mathrm{i}}$ of the fibre and satisfy $0 \leq X_{\mathrm{i}} \leq X_{0}, 0 \leq Y_{\mathrm{i}} \leq Y_{0}$, and 0 $\leq Z_{\mathrm{i}} \leq Z_{0}$.

Step 2. Establish and rotate a local coordinate system at ki.
Step 2-1. At the fibre starting point $K_{\mathrm{i}}$, establish a local coordinate system $K_{\mathrm{i}} X^{\prime} Y^{\prime} Z^{\prime}$.

Step 2-2. Switch the local coordinate system $\mathrm{KiX}^{\prime} \mathrm{Y}^{\prime} \mathrm{Z}^{\prime}$ to the current coordinate system. Keep the origin (Ki) of the local coordinate system $\mathrm{KiX}^{\prime} \mathrm{Y}^{\prime} \mathrm{Z}^{\prime}$ unchanged, and rotate the $\mathrm{X}^{\prime}$ axis, $\mathrm{Y}^{\prime}$ axis, and $\mathrm{Z}^{\prime}$ axis of the local coordinate system $\mathrm{KiX}^{\prime} \mathrm{Y}^{\prime} \mathrm{Z}^{\prime}$ at random angles;

Step 3. Generation of fibre end point $K_{\mathrm{j}}$.

Step 3-1. The fibre end point $K_{\mathrm{j}}$ is generated at the point $\left(l_{f}, 0\right.$, 0 ) of the rotated local coordinate system $K_{\mathrm{i}} X^{\prime} Y^{\prime} Z^{\prime}$, where $l_{f}$ is the length of the fibre.

Step 3-2. Switch the local coordinate system to the global coordinate system. In the global coordinate system, extract the coordinates of the fibre end point $K_{\mathrm{j}}$.

(1) If it satisfies, $0 \leq X_{\mathrm{j}} \leq X_{0}, 0 \leq Y_{\mathrm{j}} \leq Y_{0}$, and $0 \leq Z_{\mathrm{j}} \leq Z_{0}$, go to Step 4.

(2) If $\mathrm{X}_{\mathrm{j}}>X_{0}$ or $\mathrm{X}_{\mathrm{j}}<{ }_{0}$ or $\mathrm{Y}_{\mathrm{j}}>Y_{0}$ or $\mathrm{Y}_{\mathrm{j}}<0$ or $\mathrm{Z}_{\mathrm{j}}>Z_{0}$ or $Z_{j}<0$, then the point is beyond the range of the matrix. Delete the point and return to Step 2-2. Rotate the local coordinate system again to regenerate the fibre end point $K_{\mathrm{j}}$ until the coordinates of the fibre end point $K_{\mathrm{j}}$ satisfy $0 \leq \mathrm{X}_{\mathrm{j}} \leq X_{0}, 0 \leq \mathrm{Y}_{\mathrm{j}} \leq Y_{0}$, and $0 \leq Z_{j} \leq Z_{0}$.

Step 4. Generation of a fibre.

Connect line $K_{\mathrm{i}}$ and $K_{\mathrm{j}}$ with line to get a randomly distributed fibre, as shown in Figure 1.

Step 5. Write Step 1-Step 4 as subroutines or macrofiles and repeat $\mathrm{N}$ calls to generate $\mathrm{N}$ fibres.

It is noteworthy that when $K_{j}$ exceeds the range of the substrate in Step 3-2, if both $K_{\mathrm{i}}$ and $K_{\mathrm{j}}$ are deleted, the starting point $K_{\mathrm{i}}$ and end point $K_{\mathrm{j}}$ of the fibre are regenerated from Step 1 , instead of regenerating end point $K_{j}$ of fibre from Step 2-2, which would have resulted in less fibre distribution at the edge of the matrix, leading to uneven fibre distribution in the matrix.

The following are the examples of fibre generation with different fibre volume ratios. The size of the substrate is $300 \mathrm{~mm} \times 150 \mathrm{~mm} \times 150 \mathrm{~mm}$. According to the abovementioned method, the fibre volume ratio $V_{f}$ of the fibre geometric model is $0.5 \%, 1.0 \%, 1.5 \%, 2.0 \%, 2.5 \%$, and $3.0 \%$. Because the geometric characteristics of the fibres used are the same, the number of fibres increases as the volume content increases. The fibre generation results are shown in Figure 2.

The orientation and distribution of fibres govern the performance of fibre reinforced concrete and play a major role in fracture results that are used to evaluate the structural competence of the composite material [35].

Figure 2 clearly indicates that as the fibre volume ratio $V_{f}$ increases from $0.5 \%$ to $3.0 \%$, the fibre distribution becomes increasingly dense. Regardless of their number, the fibres can be guaranteed to be randomly and uniformly distributed in the matrix. 


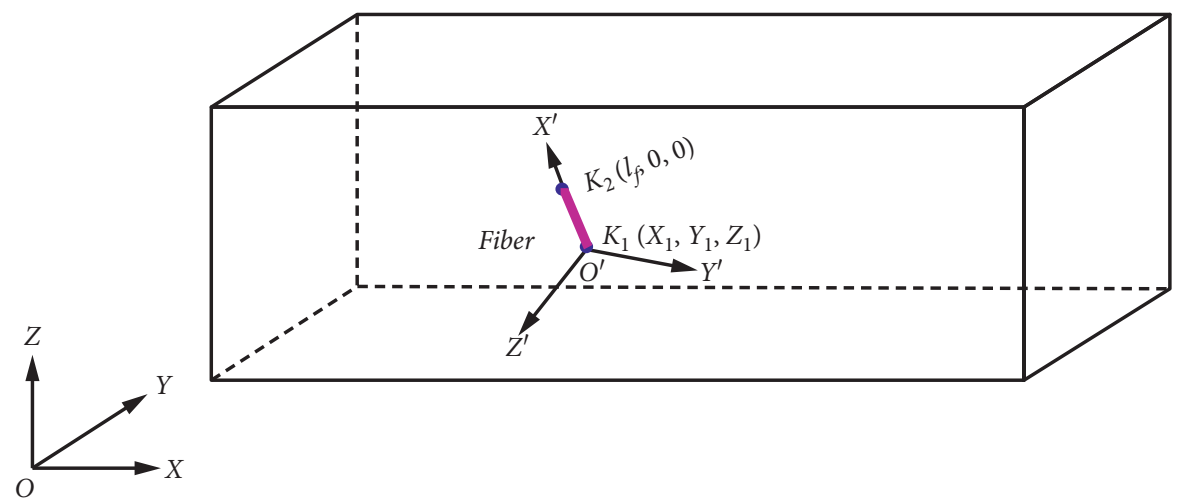

Figure 1: Generation of a fibre.

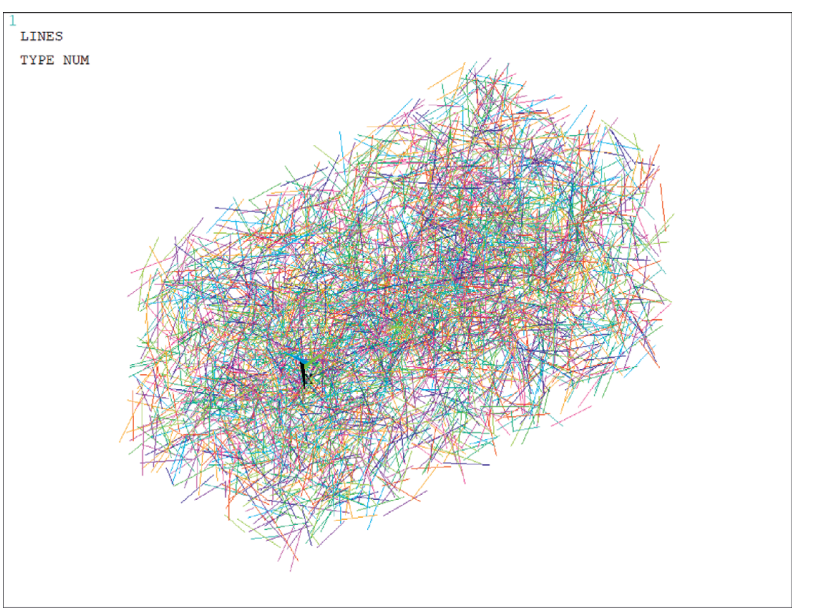

(a)

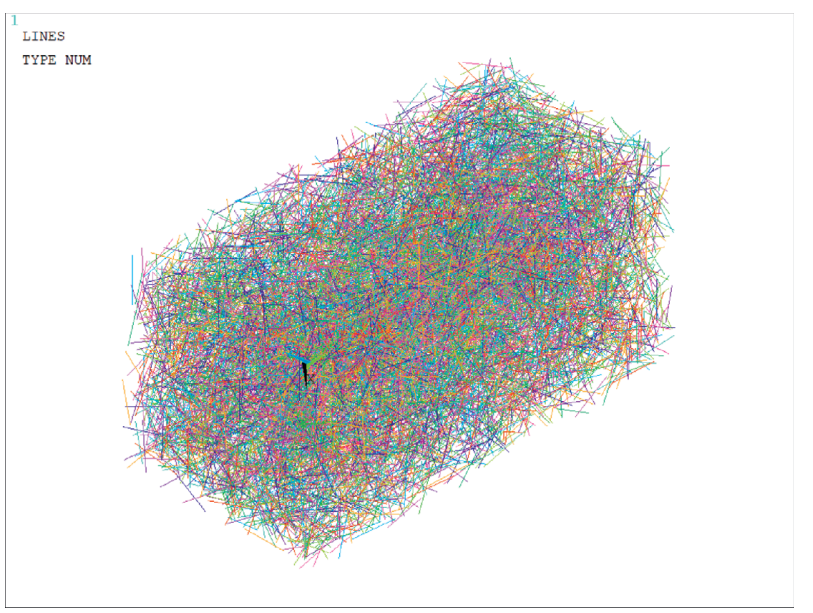

(c)
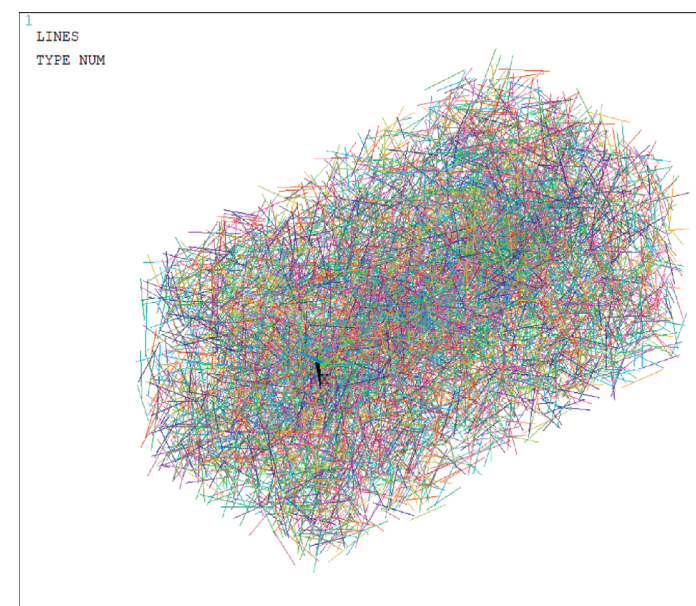

(b)

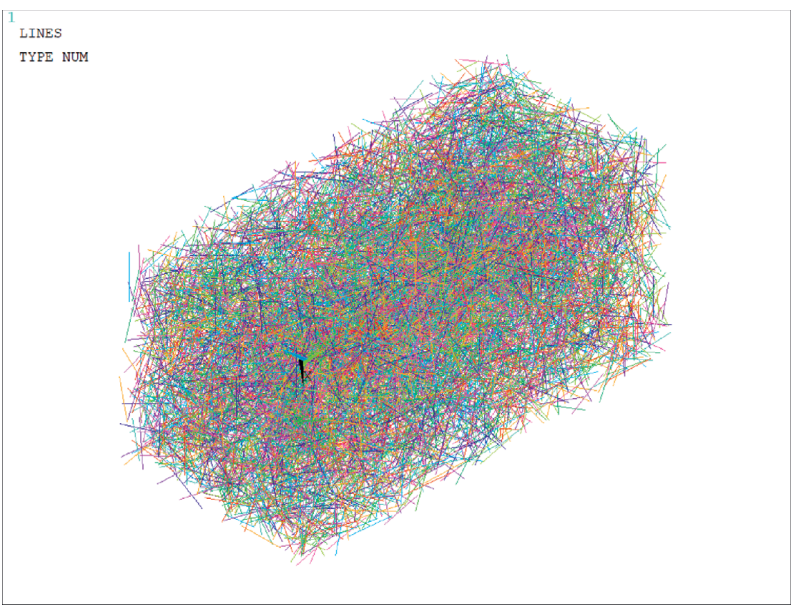

(d)

Figure 2: Continued. 


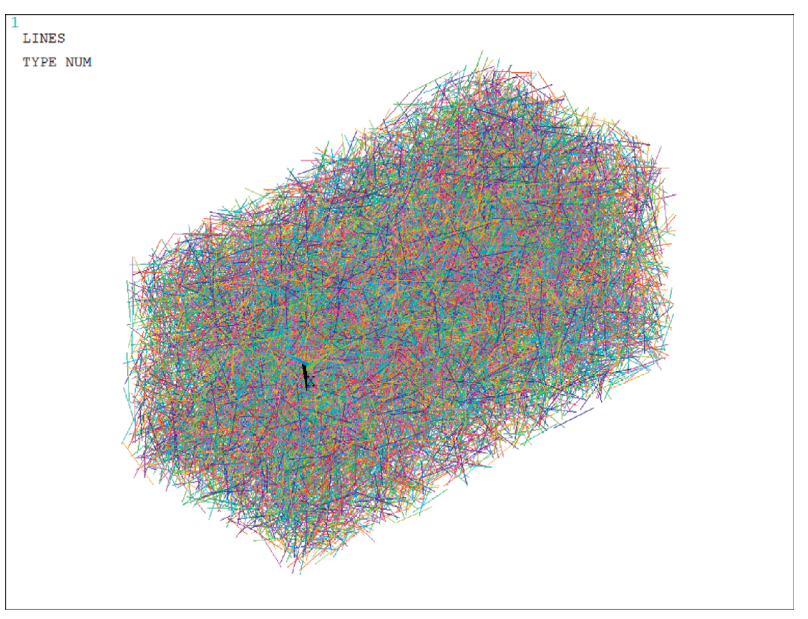

(e)

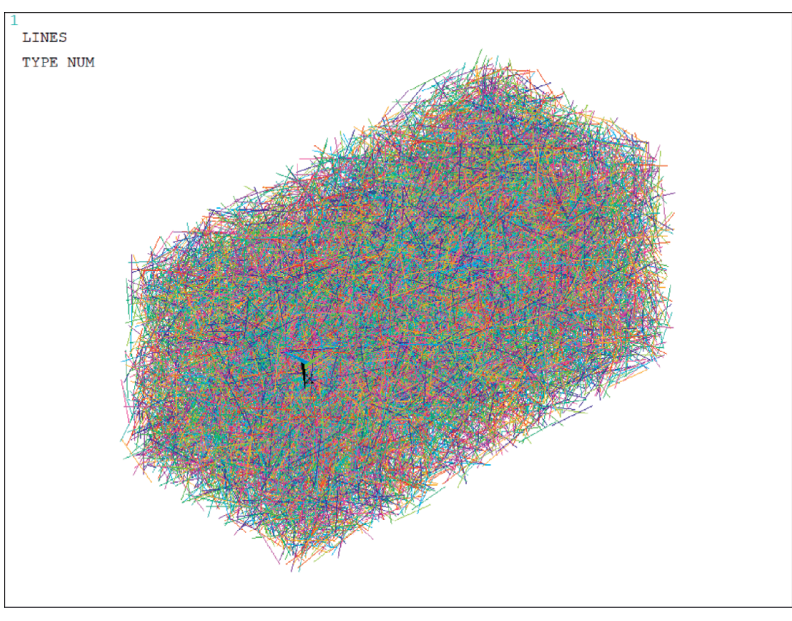

(f)

FigURE 2: Fibre generation with different fibre volume ratios. (a) $V_{f}=0.5 \%$. (b) $V_{f}=1.0 \%$. (c) $V_{f}=1.5 \%$. (d) $V_{f}=2.0 \%$. (e) $V_{f}=2.5 \%$. (f) $V_{f}=3.0 \%$.

\section{Three-Dimensional SFRC Meso-Scale Numerical Model}

3.1. Modelling. The geometric model of the fibre generated by ANSYS is exported in the Initial Graphics Exchange Specification (IGES) format, which can be simulated in professional finite element software. This study uses midas FEA to calculate and analyse the SFRC structure.

Firstly, import the geometric model of steel fibre in IGES format and then define the steel fibre as rebar elements. The steel fibre was modelled using embedded rebar elements that added the stiffness of the reinforcement to the parent elements. The basic properties of steel fibre include position information, shape information, and physical properties, without degrees of freedom. The midas FEA can realise the automatic coupling of steel and concrete, so an SFRC mesoscale analysis model is established. Figure 3 shows the threedimensional meso-scale numerical model of an SFRC beam established in midas FEA. In the model, elastic blocks are added at the support and displacement loading to prevent stress concentration.

3.2. Constitutive Relation of Concrete. Concrete crack analysis methods include discrete crack model and smeared crack model. The advantage of the discrete crack model is that it can specifically simulate the discontinuity caused by the crack, bond slip between steel bar, and concrete. However, the accuracy of the analysis is greatly affected by the input parameters, and the finite element modelling is relatively complicated. The smeared crack model assumes that the local cracks are distributed in a certain range. It is generally used on reinforced concrete structures with a large number of steel bars. Its advantage is that the modelling is relatively simple.

The total strain crack model in the smeared crack model can be used in midas FEA [36], whose advantages are as follows: (1) crack distribution is convenient to show and the crack unit does not separate at the crack position; (2) the crack direction changes with the direction of the main strain, only the normal stress is generated on the crack surface, and the calculation process is simpler. The total strain crack model has many satisfactory examples in analysing concrete structures [37, 38]. The parabolic model of the total strain crack model is a commonly used model for the constitutive relationship of concrete under compression. The parabolic model was based on the fracture energy theory [39]. As shown in Figure 4, the model is determined by three parameters: concrete compressive strength $f_{c}$, fracture energy $G_{c}$, and characteristic element length $h$.

The calculation formula of $G_{\mathrm{c}}$ is shown in the following equation:

$$
G_{c}=G_{\mathrm{co}}\left(\frac{f_{c}}{f_{\mathrm{cmo}}}\right)^{0.7} .
$$

In equation (1), $f_{\text {cmo }}$ is the benchmark average compressive strength, and its value is $10 \mathrm{~N} / \mathrm{mm}^{2}$. $G_{\text {co }}$ is related to the maximum aggregate size, and the corresponding relationship is listed in Table 1.

The peak strain $\varepsilon_{0}$ corresponding to the concrete compressive strength $\mathrm{fc}$ is shown in the following equation:

$$
\varepsilon_{0}=\frac{4}{3} \frac{f_{c}}{E_{c}} .
$$

Characteristic element length $h$ can be obtained by equation (3) according to the ultimate compression strain at the softening stage $\varepsilon_{\mathrm{cu}}, \varepsilon_{0}$, and $G_{c}$ :

$$
h=\frac{3}{2} \frac{G_{c}}{\left(\varepsilon_{\mathrm{cu}}-\varepsilon_{0}\right) f_{c}} .
$$

Tensile models of concrete in total strain crack models such as constant, elastic, brittleness, linear, exponential, Hordijk, and multilinear models are provided in midas FEA. This study uses a multilinear model. When the concrete 


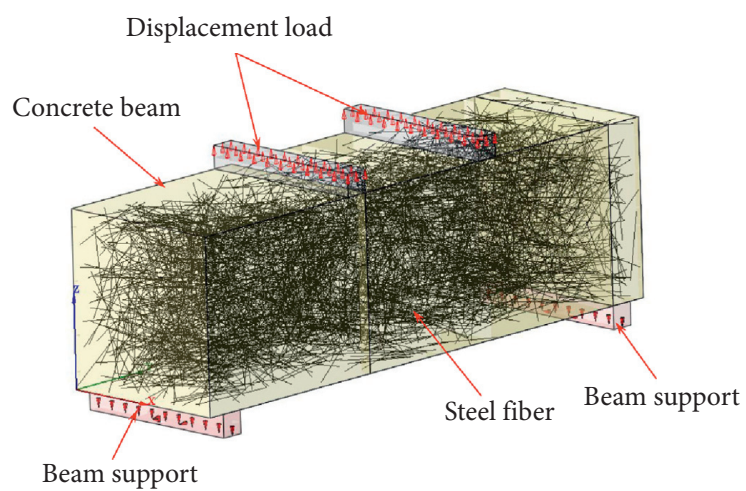

FIgURE 3: Three-dimensional meso-scale numerical model of an SFRC beam.

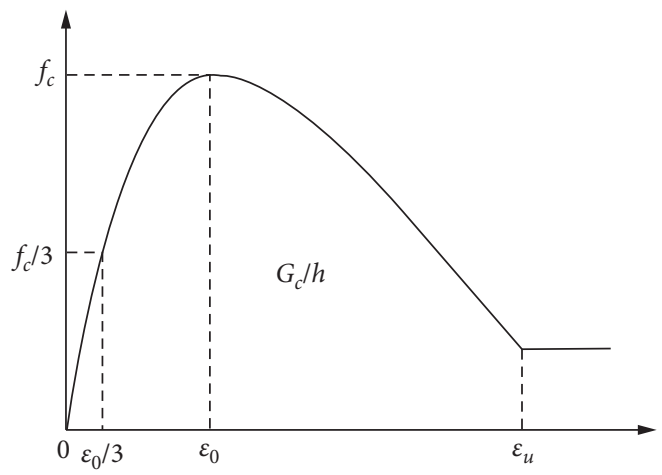

FIgURE 4: Compression constitutive relations of the parabolic model.

TABLe 1: Relationship between $G_{\text {co }}$ and maximum aggregate size [36].

\begin{tabular}{lc}
\hline$D_{\max }(\mathrm{mm})$ & $G_{\mathrm{co}}\left(\mathrm{J} / \mathrm{m}^{2}\right)$ \\
\hline 8 & 23 \\
16 & 30 \\
32 & 58 \\
\hline
\end{tabular}

tensile strength is exceeded, softening occurs according to a user-defined polyline, as shown in Figure 5.

3.3. Bond Slip of Concrete and Steel Fibre. Studies show that the primary form of fibre failure is the steel fibre being pulled out of the matrix rather than breaking. That is, the strength required to pull out the steel fibre is lower than the yield strength of the steel fibre. The steel fibres strength of the pulled out can be obtained by testing or correctly simulating the bond slip between the fibre and the matrix. However, both experiments and numerical values are very difficult to achieve.

The bond slip of steel fibre is complex. Therefore, this study adopts nominal yield strength $\overline{f_{y}}$ equivalent bond slip between the fibre and the matrix. Based on the abovementioned reasons, in the numerical analysis process of this study, it is not necessary to consider the bond-slip behaviour between steel fibre and concrete. In Section 3.4, the idea and method of nominal yield strength $\overline{f_{y}}$ equivalent bond slip between the fibre and the matrix will be described in detail.

3.4. Nominal Yield Strength of Steel Fibre. Studies show that the primary form of fibre failure is it being pulled out rather than broken, which results from the high tensile yield strength of steel fibre and tests. The bond slip of steel fibre after tension is a very complex process. Many scholars have performed research work in this field [40-44]. Timon [43] considered the bond behaviour through the discrete crack model. Timon [44] used the bond model developed by Rabczuk and Belytschko to study the cohesive crack method of reinforced concrete structures.

Studies [41, 45-49] indicated that there are six different stages in the bond slip process of hooked-end steel fibre (Figure 6), namely, elastic stage (point $a$ ), partly debonded stage (point $b$ ), fully debonded stage (point $c$ ), pullout stage 1 (point $d$ ), pullout stage 2 (point $e$ ), and pullout stage 3 (point f).

When the full debonding phase is reached (point $c$ ), the bond between the fibre and the matrix cannot resist the pullout load and the bond between the fibre and the matrix is destroyed and the fibre reaches the critical pullout status and the peak load at point $c$.

In the analysis of the three-dimensional meso-scale numerical SFRC beam model, it is difficult to simulate the bond slip of steel fibre. Therefore, the von Mises model is 


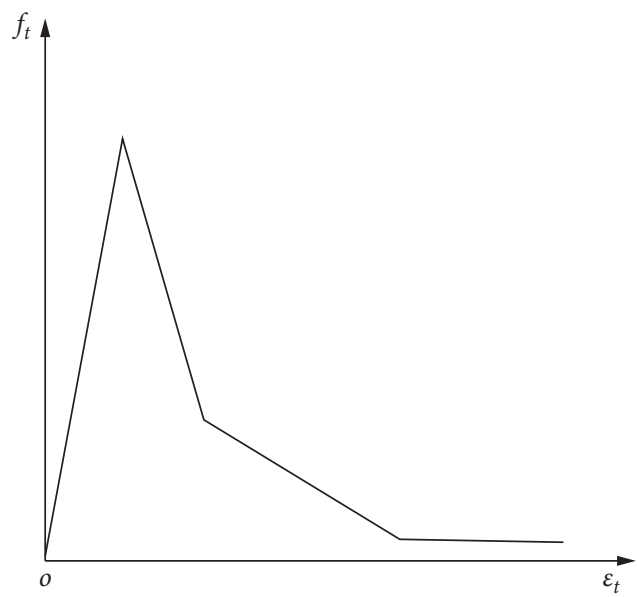

Figure 5: Tensile constitutive relations of a multilinear model.

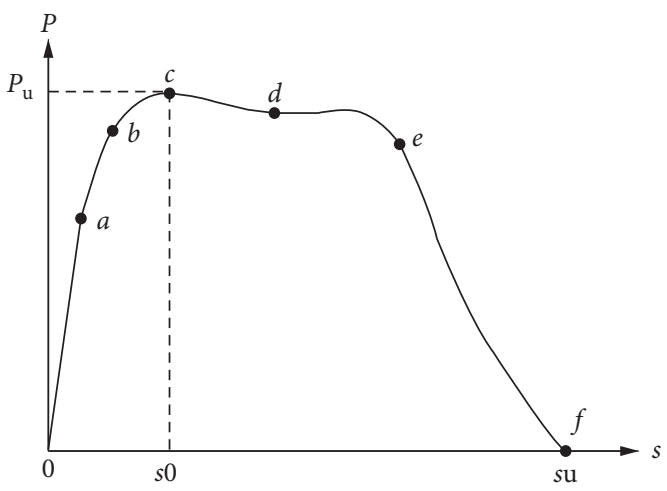

Figure 6: Bond slip of steel fibres.

proposed as an equivalent to the bond slip of the steel fibre, as shown in Figure 7, where the nominal yield strength $\overline{f_{y}}$ of the von Mises model steel fibre is

$$
\overline{f_{y}}=\frac{P_{u}}{A_{f}}(\mathrm{MPa}),
$$

where $P_{u}$ is the maximum pullout force of steel fibre $(N) ; A_{f}$ is the sectional area of steel fibre $\left(\mathrm{mm}^{2}\right)$.

The basis and advantages of simplifying the bond slip constitutive model of fibre to an ideal elastic-plastic model are as follows:

(1) The maximum pullout force of the bond slip of steel fibre is consistent with the nominal yield strength $\overline{f_{y}}$ of steel fibre. Therefore, the ultimate bearing capacity of the SFRC structure is also consistent;

(2) If the bond slip model is used, the actual geometric shape and surface shape of steel fibre should be considered. However, in this study, the ideal elastic-plastic constitutive model is used instead of the fibre bond slip curve. In the program, only the nominal yield strength $\overline{f_{y}}$ of the steel fibre is input, which avoids the modelling of the fibre shape in the finite element program and is very convenient and fast;
(3) In this study, the bond slip constitutive model of steel fibre is simplified as an ideal elastic-plastic model. If the bond slip curve of steel fibre is to be closer, the multilinear tensile model can also be used to simulate it;

(4) For different types of fibre, the maximum pullout force of steel fibre is different, and the nominal yield strength $\overline{f_{y}}$ is also different, which can be obtained by testing or consulting related research.

\section{Validation of SFRC Meso-Scale Numerical Analysis Method}

4.1. Overview of SFRC Beam Flexural Test. DINH [50, 51] conducted a series of four-point flexural tests of SFRC beams. The size of the specimens is $6 \times 6 \times 20$ inches, that is, $152.4 \mathrm{~mm} \times 152.4 \mathrm{~mm} \times 508 \mathrm{~mm}$. The loading rate is 0.005 inches $(0.127 \mathrm{~mm})$ per second. The loading is stopped when the midspan deflection reaches 0.12 inches $(3.048 \mathrm{~mm})$. The loading test setup is shown in Figure 8.

The characteristics of the three fibres used in the test are shown in Table 2. Among them, ZP305 and RC80/60BN are conventional strength fibres, which are widely used in traditional SFRC. The RC80/30BP fibre has a high yield strength of $2300 \mathrm{MPa}$. 


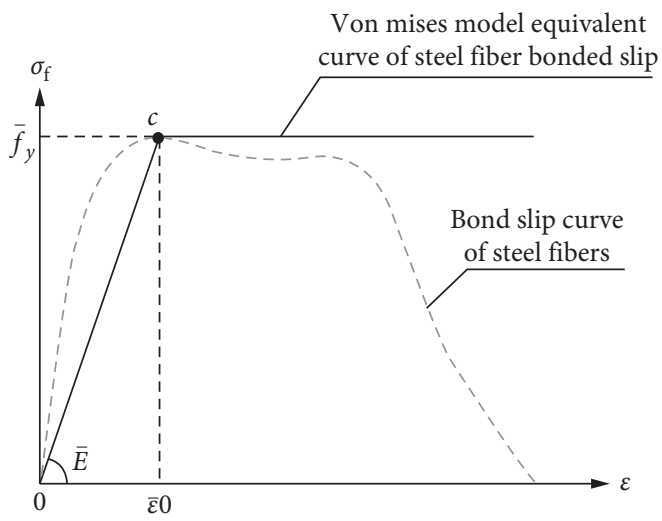

Figure 7: Equivalent von Mises model of steel fibre bonded slip.

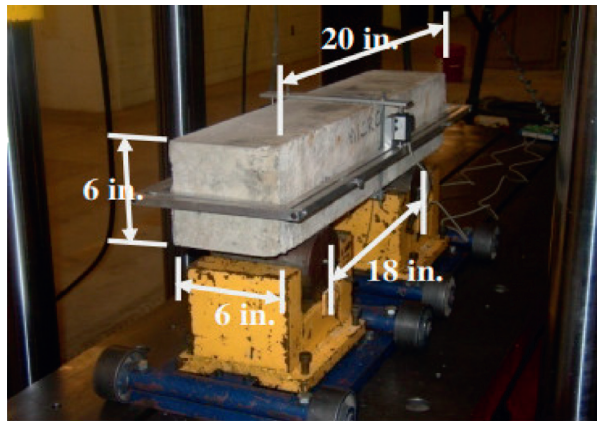

(a)

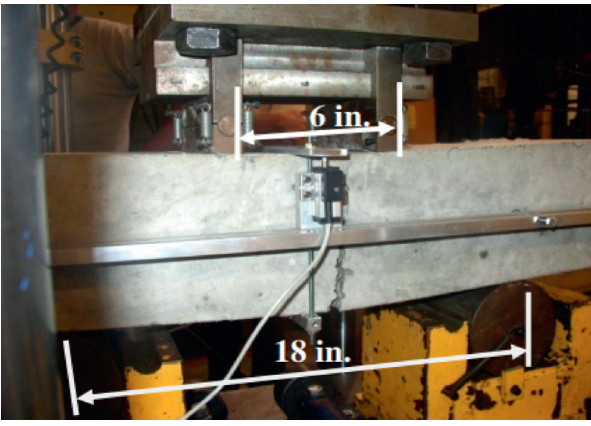

(b)

Figure 8: Four-point flexural tests of SFRC beams: (a) end view; (b) side view.

Table 2: Properties of steel fibres.

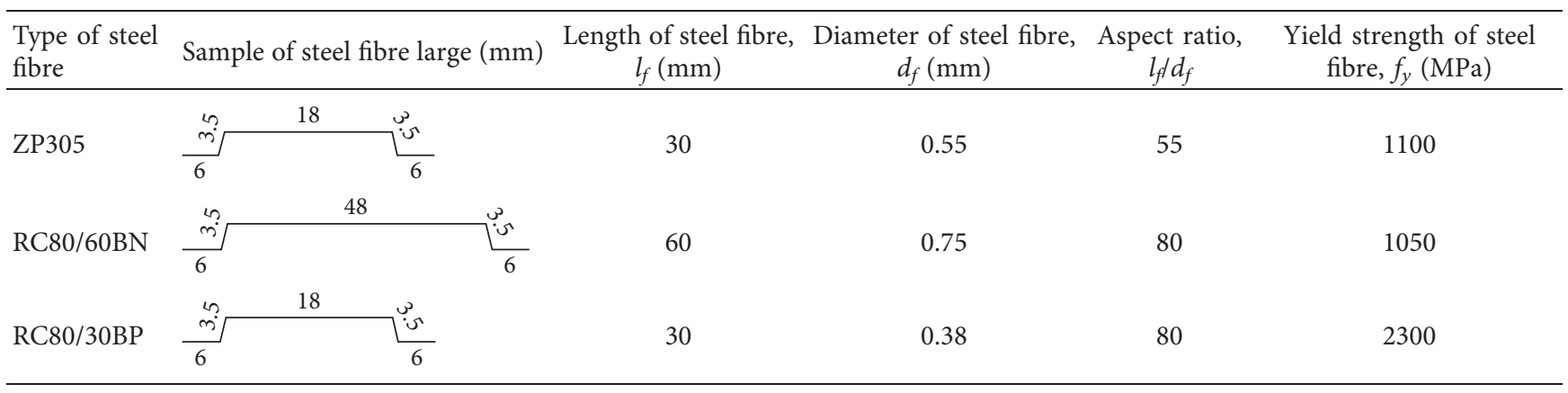

There are 5 groups of tests, each group has 4 test beams. The primary parameters of the test beams are shown in Table 3:

The method described in Section 3.1 is used to build the three-dimensional meso-scale numerical models of SFRC beams. Displacement load value is $-3.05 \mathrm{~mm}$. The established finite element model is shown in Figure 3.

\subsection{Meso-Scale Numerical Analysis of Flexural Test}

4.2.1. Load-Displacement Curve. Extract the result of mesoscale numerical analysis of the flexural test to obtain the load-displacement curve, and compare it with the test value, as shown in Figure 9. Experimental and numerical analysis data can be obtained on the ResearchGate website [52].

The load-displacement curves show that the meso-scale numerical simulation results are in good agreement with the average test values. For the M_1 group, the peak loads of the test and numerical analysis are $42.4 \mathrm{kN}$ and $42.1 \mathrm{kN}$, respectively, with a difference of $0.7 \%$. The deformation and ductility of SFRC beams are also well simulated.

4.2.2. Stress of Steel Fibre. The three-dimensional SFRC meso-scale numerical model is composed of a concrete matrix and randomly distributed steel fibres. Therefore, the analysis result can intuitively obtain the stress state and role 
TABle 3: Primary parameters of steel fibre concrete flexural beams.

\begin{tabular}{|c|c|c|c|c|}
\hline Specimen label & Dimension $(\mathrm{mm})$ & Type of steel fibre & Fibre volume ratio, $V_{f}(\%)$ & Nominal yield strength of steel fibre, $\overline{f_{y}}[42](\mathrm{MPa})$ \\
\hline$\overline{M \_1}$ & & $\mathrm{RC} 80 / 60 \mathrm{BN}$ & 0.75 & 735 \\
\hline M_2 & & $\mathrm{RC} 80 / 60 \mathrm{BN}$ & 1.5 & 367.5 \\
\hline M_3 & $508 \times 152.4 \times 152.4$ & ZP305 & 0.75 & 385 \\
\hline M_4 & & ZP305 & 1.5 & 192.5 \\
\hline M_5 & & $\mathrm{RC} 80 / 30 \mathrm{BP}$ & 0.75 & 805 \\
\hline
\end{tabular}

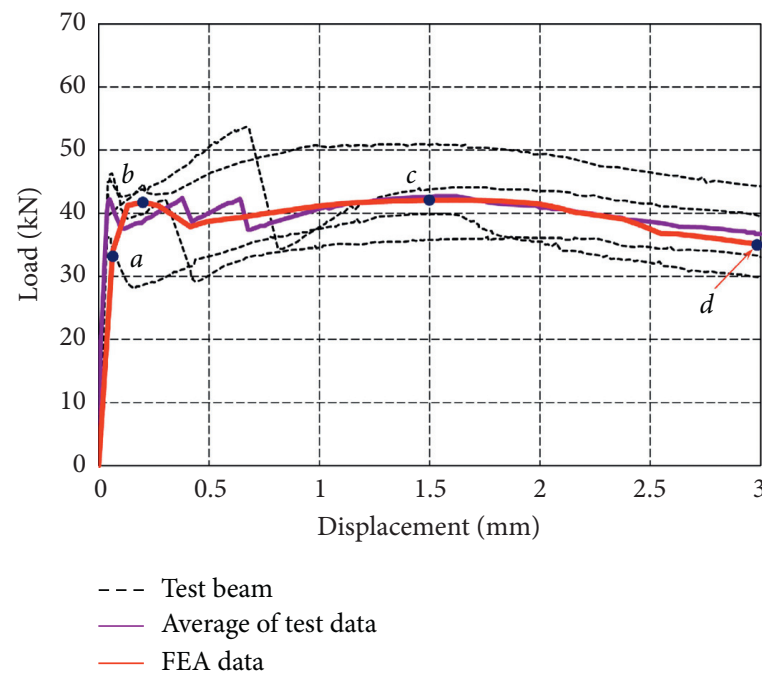

(a)

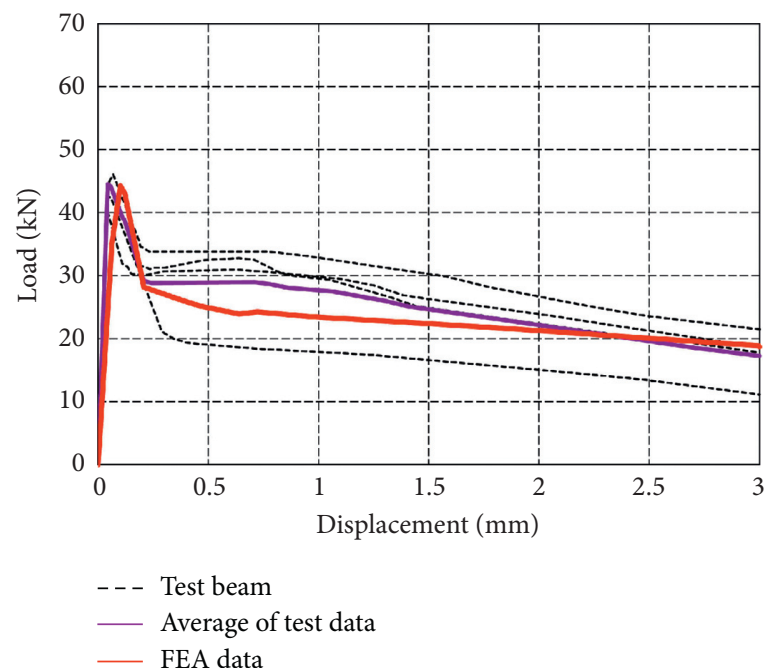

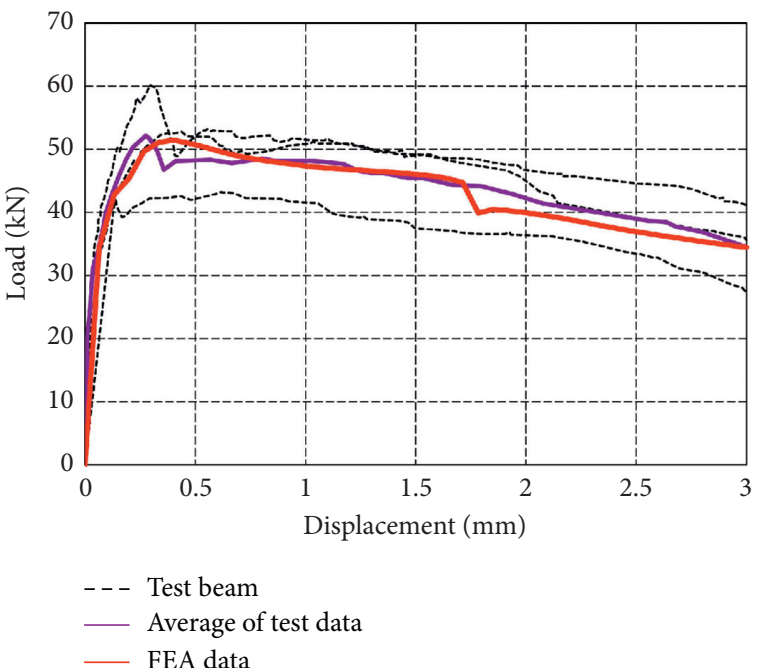

(b)

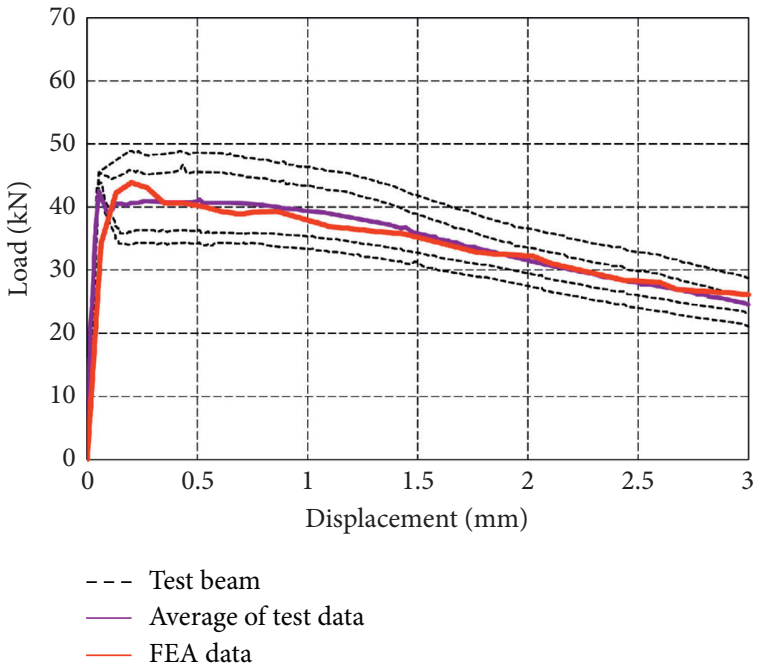

(d)

Figure 9: Continued. 


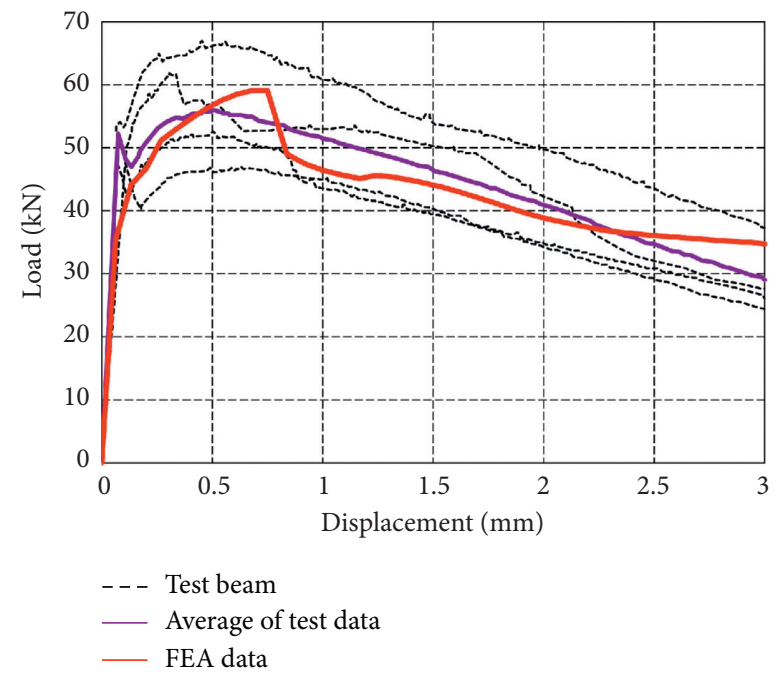

(e)

Figure 9: Test results compared with meso-scale numerical simulation results. (a) M_1. (b) M_2. (c) M_3. (d) M_4. (e) M_5.

of the steel fibre during the loading process. The following uses the M_1 group as an example.

M_1 group uses RC80/60BN type steel fibre and the fibre volume ratio is $0.75 \%$. As shown in Figure $8(\mathrm{a})$, four characteristic points are selected during the loading process to observe the process of steel fibre stress changes.

(i) Point $a: 0.8 \mathrm{Pu}$, FEM point $(\mathrm{Pu}, \mathrm{FEM}$ is the ultimate bearing capacity of the SFRC beam)

(ii) Point $b$ : $1.0 \mathrm{Pu}$, FEM point

(iii) Point $c$ : the midspan deflection reaches $1.5 \mathrm{~mm}$

(iv) Point $d$ : the midspan deflection reaches $3.0 \mathrm{~mm}$

Figure 10 is the stress diagram of the steel fibre corresponding to the four characteristic points in the load-displacement curve.

At point $a$, the microcracks in the concrete gradually expanded, and the concrete showed a certain plasticity. At this moment, the corresponding vertical load value was approximately $33.9 \mathrm{kN}$, which is close to the maximum bearing capacity of the plain concrete beam (approximately $33.8 \mathrm{kN}$ ). Because steel fibres limit the effect of crack propagation, the specimen can continue to bear the load. Figure 10(a) shows that the maximum tensile stress and maximum compressive stresses of the steel fibre are $39.4 \mathrm{MPa}$ and $-44.2 \mathrm{MPa}$, respectively. At this moment, the stress level of the steel fibre is low; in addition, the fibre stress is consistent with the stress of the concrete beam, with the upper part under compression and the lower part under tension.

When the ultimate bearing capacity is reached (point $b$ ), the stress of the steel fibre increases rapidly, which can be obtained from Figure 10(b). At this time, the maximum tensile stress of the steel fibre is about $750.0 \mathrm{MPa}$, and the maximum compressive stress is about $-109.3 \mathrm{MPa}$. The stress of the steel fibre in the tensile zone increases rapidly. The concrete in the tensile zone exits the work, and the steel fibre in the tensile zone reaches the nominal yield strength.
The loading mechanism uses vertical displacement. As the vertical displacement further increases, more steel fibres participate in bearing the load.

The two main cracks formed under the two loading points. Due to the action of the steel fibres, the SFEC beam shows good ductility, as shown in point $c$ and point $d$ in Figure 10.

According to the analysis, the stress development process of the steel fibre in the SFRC beam can be clearly displayed, and the steel fibre stress at each stage and location can be viewed.

4.2.3. Crack. In the meso-scale numerical model of the SFRC beam, concrete adopts the total strain crack model, which can well reflect the mechanical properties of concrete, including the process of crack generation and development, and output crack width.

Figure 11 shows the crack development of the beam at point $b$. At this time, the maximum crack width of the beam is $0.024 \mathrm{~mm}$, which indicates that the steel fibre has a good constraint on the crack development.

4.3. Meso-Scale Numerical Analysis of Direct Tensile Test. DINH [50] also carried out the direct tensile test of steel fibre concrete beam. The direct tensile member is a dog-boneshaped member, and the MTS testing machine is used for tensile loading. The member size and test device are shown in Figure 12.

There are 3 groups of tests, each group has 4 test beams. The primary parameters of the test beams are shown in Table 4:

Using the modelling method and material constitutive model described in Section 3, the randomly distributed steel fibre geometry model generated in ANSYS is imported into midas FEA. The bottom end of the model is fixed by the boundary conditions, and a 

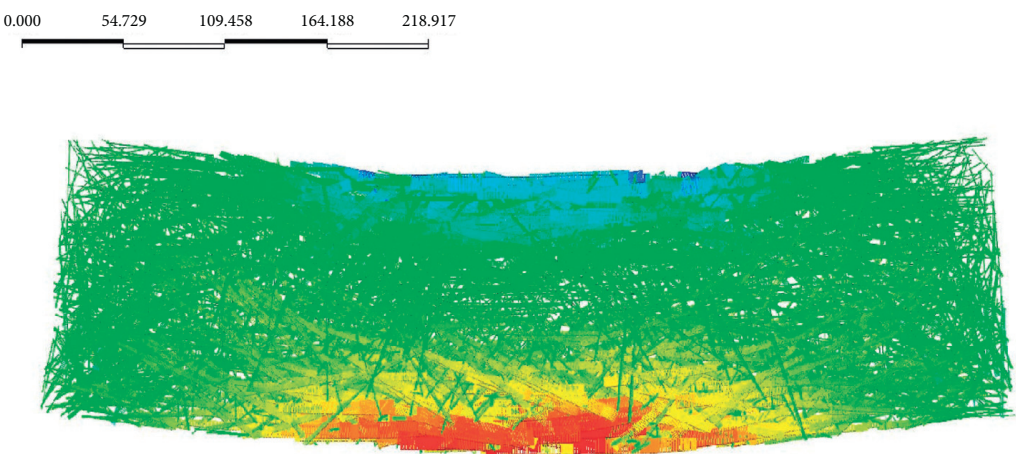

(a)

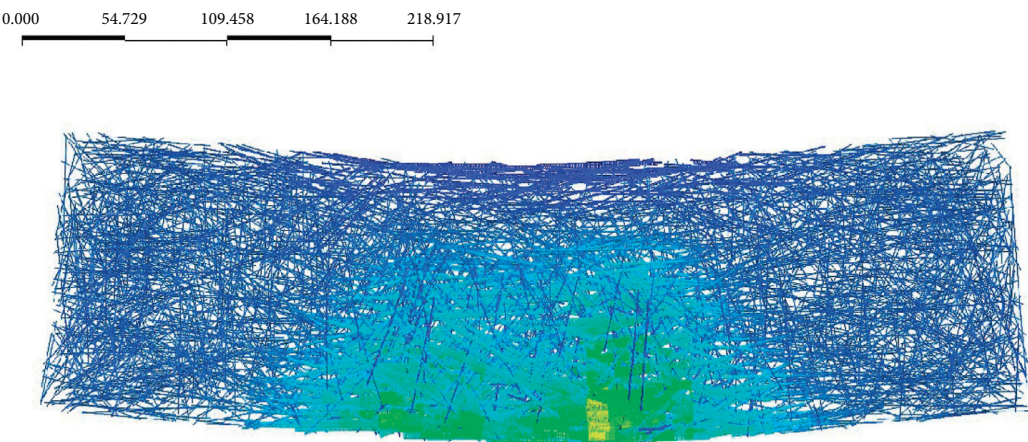

(b)

0.000
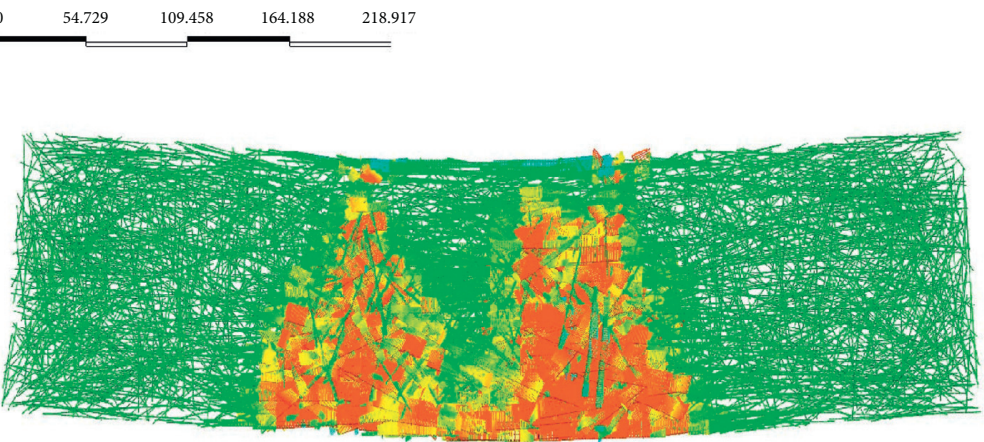

(c)

Figure 10: Continued.
Midas FEA

1D reinforcement

$\mathrm{Sxx}, \mathrm{Nmm}^{2}$

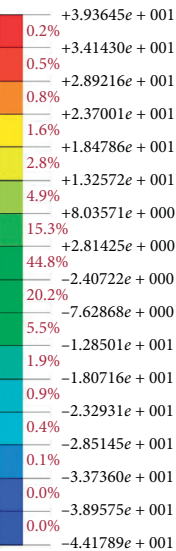

$-4.41789 e+001$

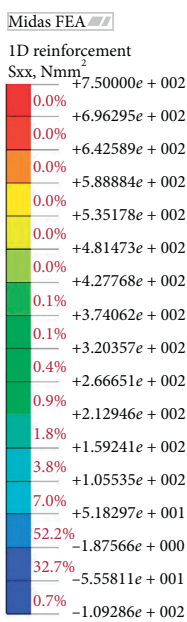

Midas FEA

ID reinforcement

Sxx, $\mathrm{Nmm}^{2}$

$9 e+002$

$0.0 \%+8.64997 e+002$

$2.7 .46455 e+002$

$5 \%+6.27913 e+002$

$3.0 \%+5.09371 e+002$

${ }^{3.7 \%}+3.90829 e+002$

${ }_{4.4 \%}+2.72287 e+002$

${ }^{5.3 \%}+1.53745 e+002$

$9.4 \%+3.52032 e+001$

$62.4 \%$

$2.9 \%-2.01881 e+002$

$-3.20423 e+002$

$0.2 \%-4.38965 e+002$

$0.1 \%-5.57507 e+002$

$0.0 \%-6.76049 e+002$

$0.0 \%-7.94591 e+002$

$0.0 \%-9.13133 e+002$ 


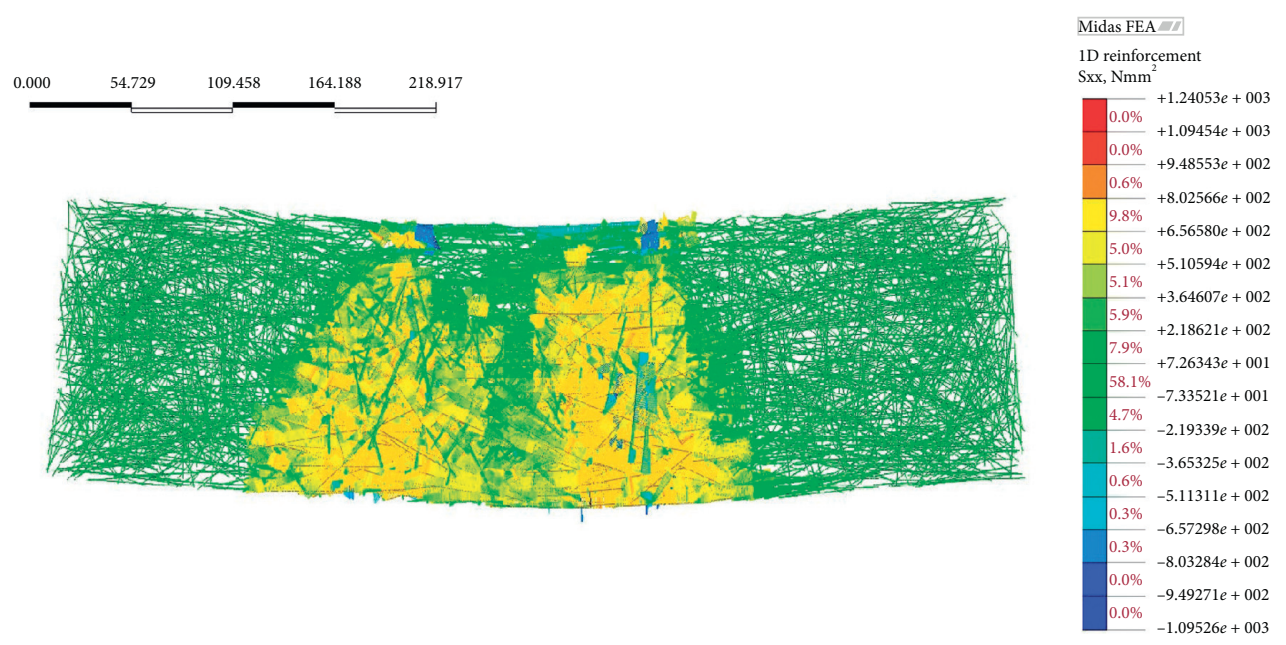

(d)

Figure 10: Steel fibre stress of M_1 beam (unit: MPa). (a) Point $a$. (b) Point $b$. (c) Point $c$. (d) Point $d$.

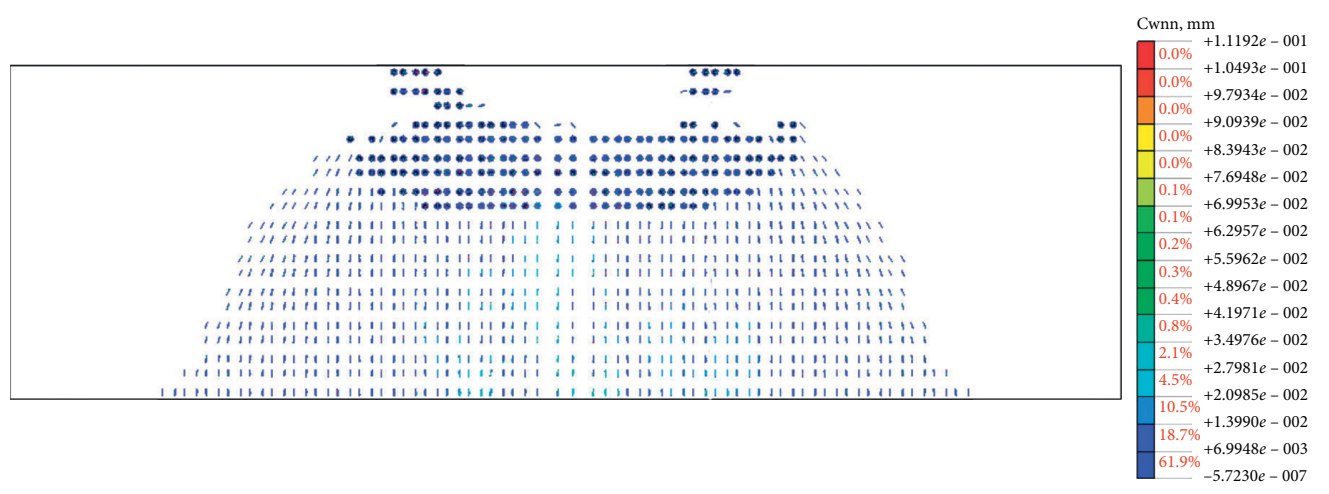

Figure 11: Crack of M_1 beam at point $b$ (unit: $\mathrm{mm}$ ).

displacement load is applied to the upper end of the model. The established finite element model is shown in Figure 13.

Load-displacement curves of meso-scale numerical tensile analysis and experiment shown in Figure 14.

The results of experiment and meso-scale numerical analysis fit well, the peak loads almost coincide, and the softening stage is also well simulated.

\subsection{Other Simulation Problems}

4.4.1. The Influence of the Random Distribution of Steel Fibres on the Results. The fibres generated in the matrix at different times have different random distributions. Whether the difference in the random distribution of steel fibres will have a big impact on the calculation results needs further research.

Taking the M_1 test group in the flexural test as an example, three groups of steel fibre models with different distributions were generated, and the results of load-displacement curves were compared. The results show that the load-displacement curves are almost completely consistent.
The abovementioned research shows that although the fibre distributions generated at different times are different, the overall fibre distribution is random and uniformly distributed, so it has little effect on the calculation results.

4.4.2. The Influence of Element Division Size on the Result. Whether the element division size of meso-scale numerical analysis model has a significant impact on the calculation results requires further study.

This paper proposes to divide the element size according to the reference fibre length. Select the specimen M-1 in Section 4.1 for the element size impact analysis. A total of 5 M-1 meso-analysis models with different element sizes have been established. The element sizes are 1/6 times, $1 / 3$ times, $1 / 2$ times, $2 / 3$ times, and 1 times the length of steel fibre, respectively.

The load-displacement curve of 5 M-1 meso-analysis models is shown in Figure 15. It can be seen that different element sizes have a certain impact on the results. The overall trend and bearing capacity of the calculation results are basically the same. However, after careful comparative analysis, it can be obtained that when the element size is 


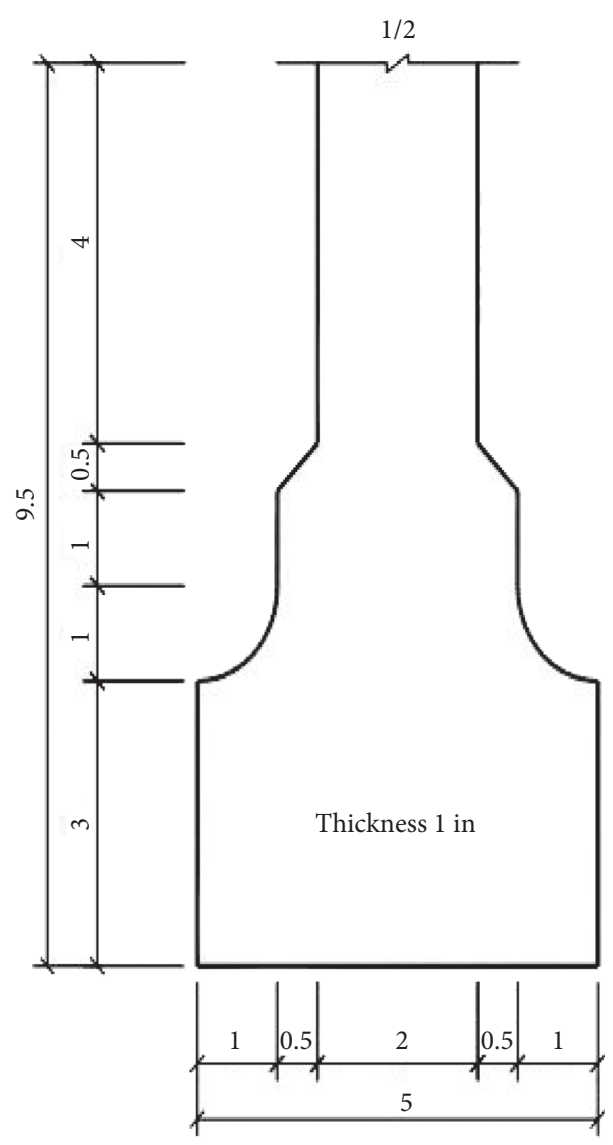

(a)

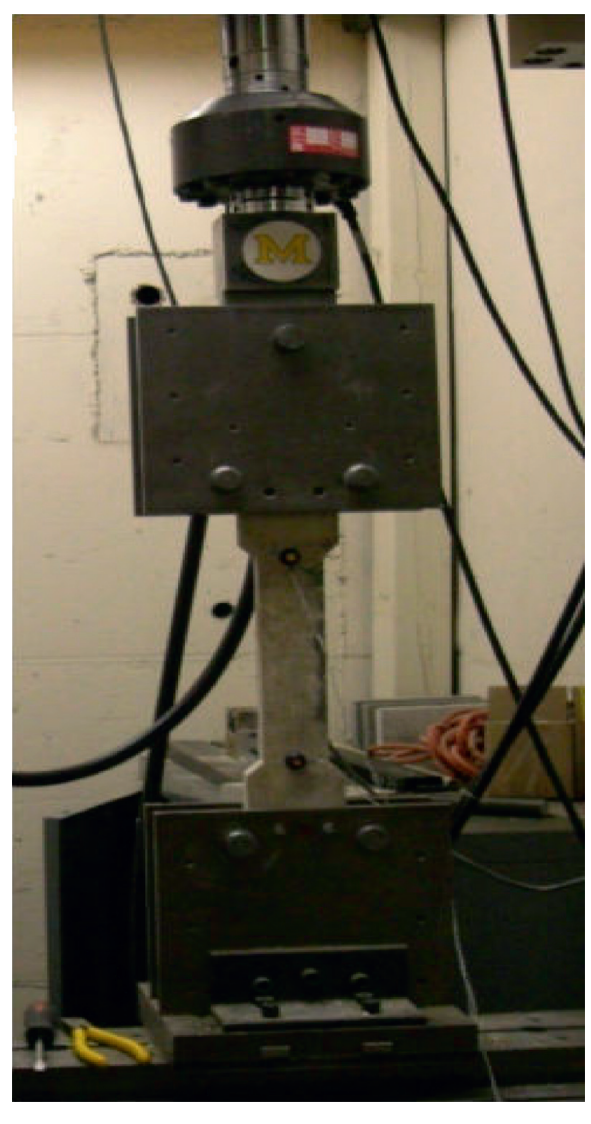

(b)

Figure 12: Direct tensile test of SFRC beams. (a) Specimen size (unit: in). (b) Test loading.

TABle 4: Primary parameters of steel fibre concrete tensile beams.

\begin{tabular}{lccc}
\hline Specimen label & Type of steel fibre & Fibre volume ratio, $V_{f}(\%)$ & Nominal yield strength of steel fibre, $\overline{f_{y}}[$ 42] $(\mathrm{MPa})$ \\
\hline T_1 & ZP305 & 0.75 & 735 \\
T_2 & RC80/30BP & 0.75 & 385 \\
T_3 & RC80/60BN & 0.75 & 805 \\
\hline
\end{tabular}

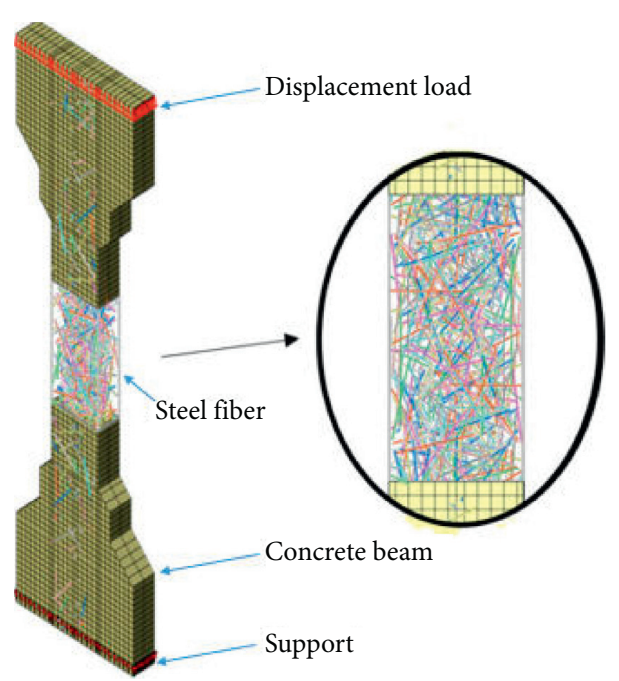

Figure 13: Meso-scale numerical model of the direct tensile test. 


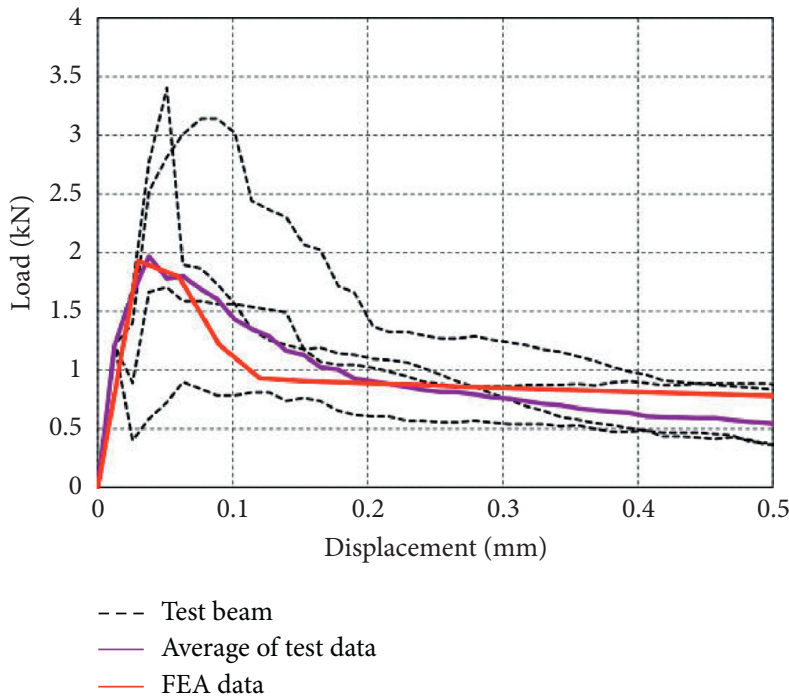

(a)

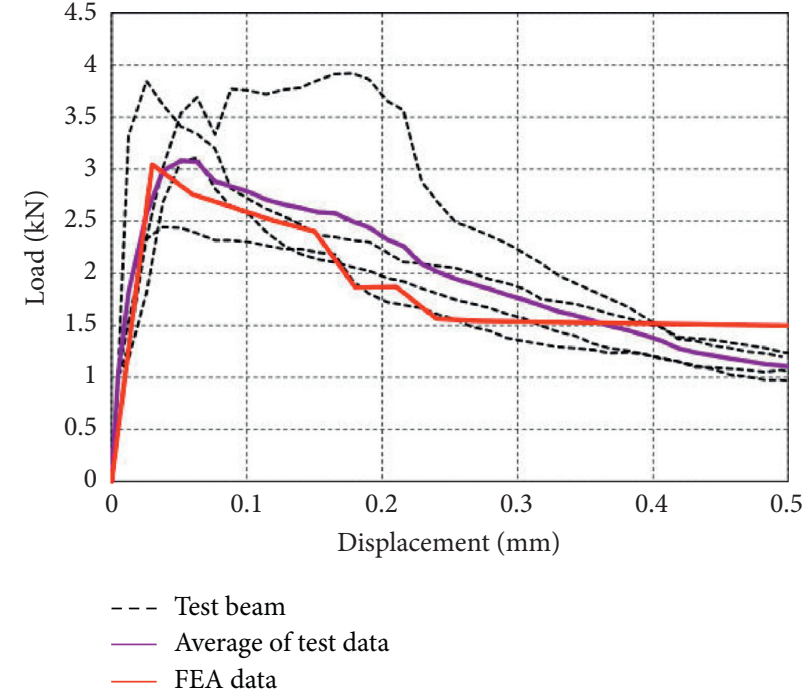

(b)

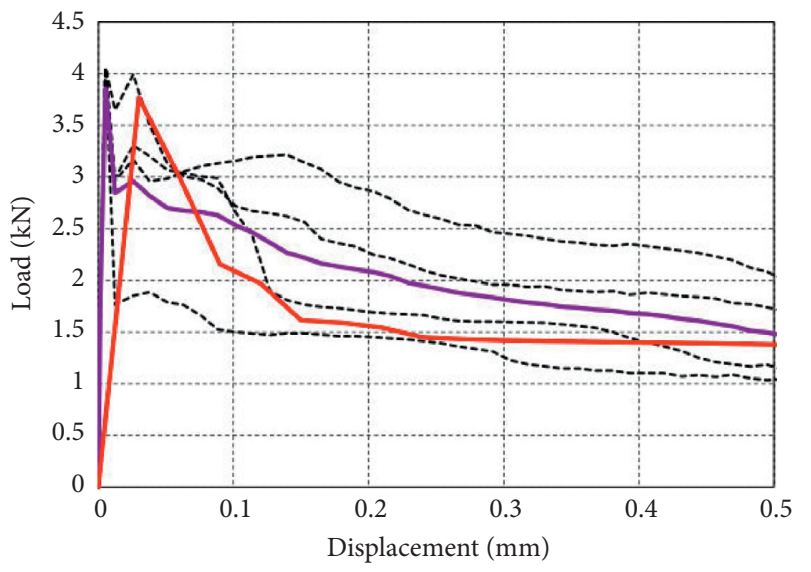

- - Test beam
_ Average of test data

(c)

Figure 14: Load-displacement curves of meso-scale numerical tensile analysis and experiment. (a) T_1. (b) T_2. (c) T_3.

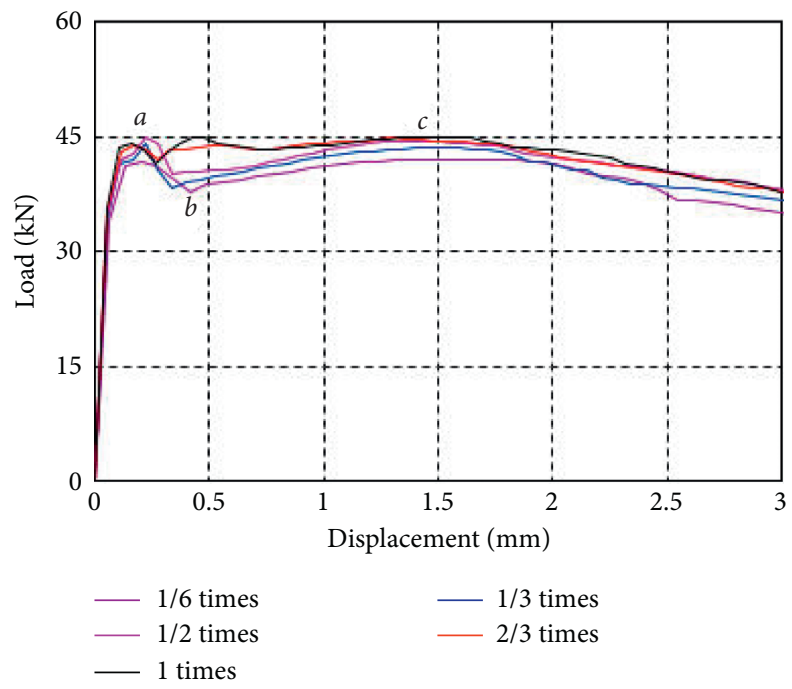

Figure 15: Load-displacement curves of M-1 element division size. 
greater than $1 / 2$ of the fibre size, after the maximum bearing capacity point $a$, there is no obvious descending segment (point $b$ ). At the same time, there is also a certain bearing capacity difference at strengthening stage (point $c$ ). Therefore, in order to ensure the accuracy of the meso-analysis results, it is recommended to divide the element size according to $1 / 2$ times the length of the steel fibre or smaller.

\section{Summary and Conclusion}

Unlike other studies, this study uses the von Mises model to consider the bond slip behaviour of steel fibres in an equivalent manner in a microlevel SFRC beam model and simulation results are in good agreement with the experimental results. The main conclusions are as follows:

(1) The steel fibre generation program developed by ANSYS is fast and efficient, and the generated steel fibres are uniformly and randomly distributed within the matrix range, and the entire concrete matrix is covered.

(2) The SFRC meso-scale model combines the concrete matrix with randomly distributed steel fibres. The concrete uses a total strain crack model, which can reflect the mechanical characteristics of concrete, especially the occurrence and development of cracks. The steel fibre is defined as a rebar element, which can realise the automatic coupling between the steel fibre and the concrete substrate.

(3) The bond-slip characteristics of steel fibres are equivalent with an ideal elastoplastic model, which can quickly realise modelling and calculation, and can well reflect the mechanical characteristics of SFRC strength and ductility;

(4) The SFRC meso-scale model can well reflect the stress changes of steel fibres during loading. The structural failure mechanism can be explained based on the changes in steel fibre stress at the meso level.

\section{Data Availability}

The data used to support the findings of this study are available from the corresponding author upon request.

\section{Conflicts of Interest}

The authors declare that they have no conflicts of interest regarding the publication of this article.

\section{Authors' Contributions}

X. W. Xue, M. Z. Wu, Y. J. Cui, and Z. W. Li performed the methodologies, supervised the study, and reviewed and edited the article. J. W. Wu performed the methodologies and investigation and wrote the original draft. X. W. Xue will be responsible for the contact work of the paper in the future.

\section{Acknowledgments}

This research was funded by the Scientific Research Project of Educational Department of Liaoning Province (LNZD202005) and the financial support from the project of the MOE Key Lab of Disaster Forecast and Control in Engineering of Jinan University, grant number 20200904005. The authors would like to thank Editage (http://www.editage.cn) for English language editing.

\section{References}

[1] X. Xue, X. Hua, and J. Zhou, "Test and prediction of shear strength for the steel fibre-reinforced concrete beams," Advances in Mechanical Engineering, vol. 11, no. 4, pp. 1-15, 2019.

[2] Ş. Yazıc1, H. Ş. Arel, and V. Tabak, "The effects of impact loading on the mechanical properties of the SFRCs," Construction and Building Materials, vol. 41, pp. 68-72, 2013.

[3] Ş. Yazıc1, G. İnan, and V. Tabak, "Effect of aspect ratio and volume fraction of steel fibre on the mechanical properties of SFRC," Construction and Building Materials, vol. 21, no. 6, pp. 1250-1253, 2007.

[4] Z. L. Wang, J. G. Wang, and Z. M. Shi, "On the strength and toughness properties of SFRC under static-dynamic compression," Composites Part B: Engineering, vol. 42, no. 5, pp. 1285-1290, 2011.

[5] S. Zhang, C. Zhang, and L. Liao, "Investigation on the relationship between the steel fibre distribution and the postcracking behaviour of SFRC," Construction and Building Materials, vol. 200, pp. 539-550, 2019.

[6] E. Poveda, G. Ruiz, H. Cifuentes, R. C. Yu, and X. Zhang, "Influence of the fiber content on the compressive low-cycle fatigue behavior of self-compacting SFRC," International Journal of Fatigue, vol. 101, pp. 9-17, 2017.

[7] X. Du, L. Jin, and G. Ma, "A meso-scale numerical method for the simulation of chloride diffusivity in concrete," Finite Elements in Analysis and Design, vol. 85, pp. 87-100, 2014.

[8] J. Xu and F. Li, "A meso-scale model for analyzing the chloride diffusion of concrete subjected to external stress," Construction and Building Materials, vol. 130, pp. 11-21, 2017.

[9] Q. Wang, W. Sun, L. Guo, C. Gu, and J. Zong, "Modeling chloride diffusion coefficient of steel fiber reinforced concrete under bending load," Advances in Civil Engineering, vol. 2018, Article ID 3789214, 6 pages, 2018.

[10] Z. Pan, A. Chen, R. Ma, D. Wang, and H. Tian, "Threedimensional lattice modeling of concrete carbonation at meso-scale based on reconstructed coarse aggregates," Construction and Building Materials, vol. 192, pp. 253-271, 2018.

[11] J. Huang, Y. Zhang, Y. Tian et al., "Research on the dynamic mechanical properties and constitutive models of steel fiber reinforced concrete and polypropylene fiber reinforced concrete," Advances in Civil Engineering, vol. 202017 pages, 2020.

[12] G.-y. Cui, J.-s. Qi, and D. Wang, "Experimental study on load bearing characteristics of steel fiber reinforced concrete lining in the soft surrounding rock tunnel," Advances in Civil Engineering, vol. 2020, Article ID 4976238, 12 pages, 2020.

[13] S. C. Seetharam, E. Laloy, A. Jivkov et al., "A mesoscale framework for analysis of corrosion induced damage of concrete," Construction and Building Materials, vol. 216, pp. 347-361, 2019. 
[14] X.-h. Shen, Q.-f. Liu, Z. Hu et al., "Combine ingress of chloride and carbonation in marine-exposed concrete under unsaturated environment: a numerical study," Ocean Engineering, vol. 189, Article ID 106350, 2019.

[15] B. Wang, R. Fang, and Q. Wang, "Flexural behavior of fiberreinforced self-stressing concrete T-shaped composite beams," Advances in Civil Engineering, vol. 2020, Article ID 8810440, 17 pages, 2020.

[16] L. Jin, H. Hao, R. Zhang, and X. Du, "Determination of the effect of elevated temperatures on dynamic compressive properties of heterogeneous concrete: a meso-scale numerical study," Construction and Building Materials, vol. 188, pp. 685-694, 2018.

[17] Y. Zhou, H. Jin, and B. Wang, "Modeling and mechanical influence of meso-scale concrete considering actual aggregate shapes," Construction and Building Materials, vol. 228, Article ID 116785, 2019.

[18] L. Zhang, J. Zhao, C. Fan, and Z. Wang, "Effect of surface shape and content of steel fiber on mechanical properties of concrete," Advances in Civil Engineering, vol. 2020, Article ID 8834507, 11 pages, 2020.

[19] Y. T. Trindade, L. A. G. Bitencourt, R. Monte, A. D. de Figueiredo, and O. L. Manzoli, "Design of SFRC members aided by a multiscale model: Part I - predicting the post-cracking parameters," Composite Structures, vol. 241, Article ID 112078, 2020.

[20] Y. T. Trindade, L. A. G. Bitencourt, and O. L. Manzoli, "Design of SFRC members aided by a multiscale model: Part II - predicting the behavior of RC-SFRC beams," Composite Structures, vol. 241, p. 112079, 2020.

[21] Z. Xu, H. Hao, and H. N. Li, "Mesoscale modelling of fibre reinforced concrete material under compressive impact loading," Construction and Building Materials, vol. 26, no. 1, pp. 274-288, 2012.

[22] Q. Fang and J. Zhang, “Three-dimensional modelling of steel fiber reinforced concrete material under intense dynamic loading," Construction and Building Materials, vol. 44, pp. 118-132, 2013.

[23] Y. Hao, X. Huang, and H. Hao, "Mesoscale modelling of concrete reinforced with spiral steel fibres under dynamic splitting tension," Advances in Structural Engineering, vol. 21, no. 8, pp. 1197-1210, 2018.

[24] M. E. Gulsan, A. Cevik, and A. E. Kurtoglu, "Stochastic finite element based reliability analysis of steel fiber reinforced concrete (SFRC) corbels," Computers and Concrete, vol. 15, no. 2, pp. 279-304, 2015.

[25] M. Sun, J. Zhu, N. Li, and C. C. Fu, "Experimental research and finite element analysis on mechanical property of SFRC T-beam," Advances in Civil Engineering, vol. 2017, Article ID 2721356, 8 pages, 2017.

[26] V. M. C. F. Cunha, J. A. O. Barros, and J. M. Sena-Cruz, "A finite element model with discrete embedded elements for fibre reinforced composites," Computers \& Structures, vol. 9495, pp. 22-33, 2012.

[27] J. Kang and J. E. Bolander, "Multiscale modeling of strainhardening cementitious composites," Mechanics Research Communications, vol. 78, pp. 47-54, 2016.

[28] F. K. F. Radtke, A. Simone, and L. J. Sluys, "A computational model for failure analysis of fibre reinforced concrete with discrete treatment of fibres," Engineering Fracture Mechanics, vol. 77, no. 4, pp. 597-620, 2010.

[29] A. Pros, P. Diez, and C. Molins, "Modeling steel fiber reinforced concrete: numerical immersed boundary approach and a phenomenological mesomodel for concrete-fiber interaction," International Journal for Numerical Methods in Engineering, vol. 90, no. 1, pp. 65-86, 2012.

[30] X. Liang and C. Wu, "Meso-scale modelling of steel fibre reinforced concrete with high strength," Construction and Building Materials, vol. 165, pp. 187-198, 2018.

[31] G. Etse, A. Caggiano, and S. Vrech, "Multiscale failure analysis of fiber reinforced concrete based on a discrete crack model," International Journal of Fracture, vol. 178, no. 1-2, pp. 131146, 2012.

[32] J. Qi, J. Wang, and Z. J. Ma, "Flexural response of highstrength steel-ultra-high-performance fiber reinforced concrete beams based on a mesoscale constitutive model: experiment and theory," Structural Concrete, vol. 19, no. 3, pp. 719-734, 2018.

[33] A. G. Bitencourt, O. L. Manzoli, T. N. Bittencourt, and F. J. Vecchio, "Numerical modeling of steel fiber reinforced concrete with a discrete and explicit representation of steel fibers," International Journal of Solids and Structures, vol. 159, pp. 171-190, 2019.

[34] S. Gang, Micromechanics Finite Element Simulation of Corrosion of UHPC Steel Fibre, Southwest Jiaotong University, Sichuan, China, 2017.

[35] M. G. Alberti, A. Enfedaque, and J. C. Gálvez, “A review on the assessment and prediction of the orientation and distribution of fibres for concrete," Composites Part B: Engineering, vol. 151, pp. 274-290, 2018.

[36] Midas IT (Beijing)Co.,Ltd., Midas FEA Analysis and Algorithm Manual, Midas IT (Beijing)Co.,Ltd., Beijing, China, 2017, http://www.MIDASUser.com.

[37] X. Xue, C. Zang, J. Zhou, and H. Zhang, "Numerical investigation of distribution laws of shear force in box girder webs," Advances in Materials Science and Engineering, vol. 2019, Article ID 9865989, 14 pages, 2019.

[38] F. Xue and X. Feng, "Spatial and temporal distribution law and influencing factors of the mining-induced deformation and failure of gas boreholes," Advances in Materials Science and Engineering, vol. 2018, Article ID 9580526, 15 pages, 2018.

[39] H. P. Feenstra, "Computational aspects of biaxial stress in plain and reinforced concrete," Civil Engineering \& Geosciences, vol. 25, no. 3, pp. 355-359, 1993.

[40] F. Isla, G. Ruano, and B. Luccioni, "Analysis of steel fibers pull-out. Experimental study," Construction and Building Materials, vol. 100, pp. 183-193, 2015.

[41] R. Ahmadi, M. Sharifi, and P. Ghoddousi, "Fibre pullout model for aligned hooked-end steel fibre," Canadian Journal of Civil Engineering, vol. 37, no. 9, pp. 1179-1188, 2010.

[42] M. Tuyan and H. Yazıc1, "Pull-out behavior of single steel fiber from SIFCON matrix," Construction and Building Materials, vol. 35, pp. 571-577, 2012.

[43] T. Rabczuk and T. Belytschko, "Cracking particles: a simplified meshfree method for arbitrary evolving cracks," International Journal for Numerical Methods in Engineering, vol. 61, no. 13, pp. 2316-2343, 2004.

[44] T. Rabczuk, G. Zi, S. Bordas, and H. Nguyen-Xuan, "A geometrically non-linear three-dimensional cohesive crack method for reinforced concrete structures," Engineering Fracture Mechanics, vol. 75, no. 16, pp. 4740-4758, 2008.

[45] Markovic, High-performance Hybrid-Fibre Concrete - Development and Utilization, Delft University of Technology, South Holland, Netherlands, 2006.

[46] F. Laranjeira, C. Molins, and A. Aguado, "Predicting the pullout response of inclined hooked steel fibers," Cement and Concrete Research, vol. 40, no. 10, pp. 1471-1487, 2010. 
[47] T. Soetens, A. Van Gysel, S. Matthys, and L. Taerwe, "A semianalytical model to predict the pull-out behaviour of inclined hooked-end steel fibres," Construction and Building Materials, vol. 43, pp. 253-265, 2013.

[48] R. Breitenbücher, G. Meschke, F. Song, and Y. Zhan, "Experimental, analytical and numerical analysis of the pullout behaviour of steel fibres considering different fibre types, inclinations and concrete strengths," Structural Concrete, vol. 15, no. 2, pp. 126-135, 2014.

[49] T. Abu-Lebdeh, S. Hamoush, W. Heard, and B. Zornig, "Effect of matrix strength on pullout behavior of steel fiber reinforced very-high strength concrete composites," Construction and Building Materials, vol. 25, no. 1, pp. 39-46, 2011.

[50] H. Dinh, Shear Behavior of Steel Fibre Reinforced Concrete Beams without Stirrup Reinforcement, The University of Michigan, Ann Arbor, MI, USA, 2009.

[51] X. Xing-wei, W. Jia-wei, and Z. Jun-long, "Comparative analysis of numerical and experimental values of SFRC in three-dimensional meso-scale," Journal of Shenyang University of Technology, vol. 40, no. 1, pp. 109-113, 2019.

[52] https://www.researchgate.net/publication/344899999_Load_ displacement_curve_of_SFRC_test_and_meso-scale_numeri cal_analysis_data. 